
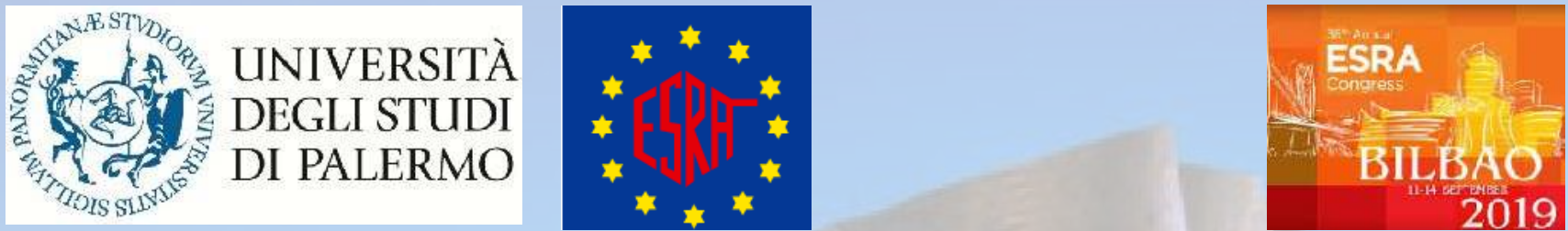

\title{
THE EFFICACY AND SAFETY OF ULTRASOUND-GUIDED SUPERFICIAL CERVICAL PLEXUS BLOCK (SCPB) IN PATIENT UNDERGOING THYROID SURGERY: A CASE REPORT
}

\author{
M.S. Oddo1, M.G. Leone1, D. Vella1, E. Ferraro1, D. Canzio 2.
}

1Section of Anaesthesia- Analgesia- Emergency- Intensive Care. Palermo University Medical Center- Italy. A. Giarratano, Full Professor

2Department of Surgical- Oncological and Oral Science Di.Chir.On.S., Palermo- Via del Vespro 129. 90127, Italy.

\section{BACKGROUND AND AIM}

The SCPB provides effective anesthesia and analgesia for the head and neck region. CPBs can be performed more safely and accurately under ultrasound guidance, which is used to easily identify various important landmarks.This case report was carried out to assess the efficacy of SCPB in reducing the intra and postoperative use of opioids/analgesics to control pain due to thyroidectomy.

\section{METHODS:}

45-year-old woman, ASA II, underwent right hemithyroidectomy under general anesthesia (sevoflorane $2 \%$ and remifentanil TCl 0.7-1 $\mathrm{ng} / \mathrm{ml}$ ). Ultrasound-guided right superficial cervical plexus block (SCPB) was performed using levobupivacaine $10 \mathrm{ml}$ 0.25\%. Pain

\section{RESULTS:}

Intraoperative analgesia was achieved with remifentanil at values lower than $1,5-2 \mathrm{ng} / \mathrm{ml}$. Hemodynamic parameters were stable during the surgery. No further perioperative analgesia was performed. Post-operative NRS was maintained between 0-3 ( $4 \mathrm{~h}-6 \mathrm{~h}=2-3$ and $12 \mathrm{~h}-24 \mathrm{~h}=2-0$ ). The patient reported hypoesthesia of the right side of the neck for the first $8 \mathrm{~h}$ post surgery.

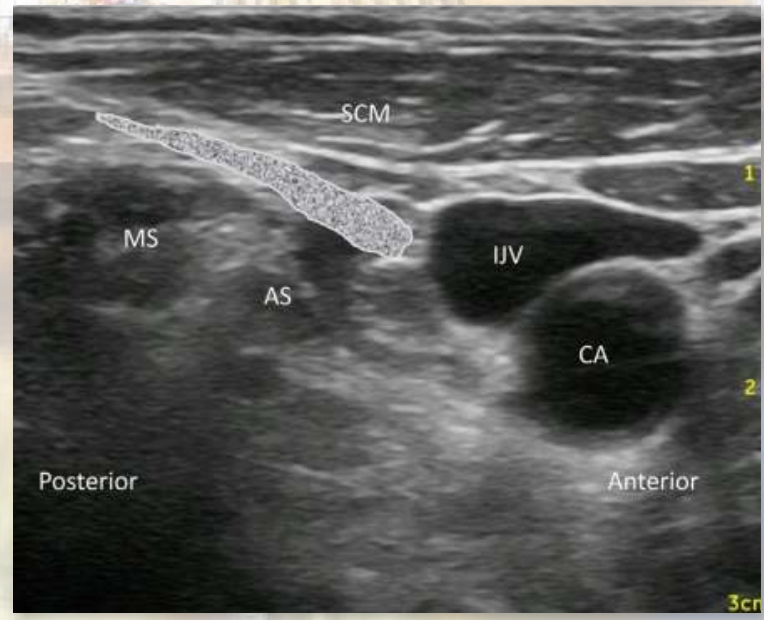

Ultrasound images of the posterior cervical space. The posterior cervical space (white mark) is a connective space between two fasciae where the superficial divisions of the cervical plexus cross. SCM: sternocleidomastoid muscle; AS: anterior scalene muscle; MS: medius scalene muscle; IJV: internal jugular vein; CA: common carotid artery.

\section{CONCLUSIONS:}

In this report, the SCPB reduces intraoperative opioids dose and patient's request of post operative pain therapy. Ultrasound guided CPB is easy to perform, safe and reliable, eliminating the occurrence of side effects and complications. Future goal for our team is to make the cervical plexus block the first choice for performing neck surgery avoiding general anesthesia.

\section{References:}

Seidel R, Schulze M, Zukowski K, Wree A. Ultrasound-guided intermediate cervical plexus block. Anatomical study 